\title{
LAS MIL FORMAS DE VENUS EN LOS DETECTIVES SALVAJES: "ANARQUÍA ERÓTICA" EN LOS DESIERTOS DE SONORA ${ }^{1}$
}

\author{
Alexis Candia Cáceres \\ Pontificia Universidad Católica de Chile \\ iacandia@uc.cl
}

"Yo era el único anarquista que conocía, gracias a dios, porque de lo contrario hubiera dejado de ser anarquista"

Roberto Bolaño.

“[...] pasajeros en tránsito por las delicias del infierno"

Néstor Perlongher.

\section{RESUMEN / ABSTRACT}

En el artículo se realiza un estudio de las manifestaciones y los significados del erotismo en Los detectives salvajes. La novela de Roberto Bolaño puede ser leída a partir de una "anarquía erótica" que tiene que ver con la exploración ritualizada del placer y que, en este sentido, está desligada de cualquier vínculo con la reproducción. Para Bolaño, el eros es una fuerza que liberaliza a hombres y mujeres, transgrediendo los patrones culturales y económicos de los discursos hegemónicos. De allí el intenso, variado y rupturista errabundeo erótico de los poetas real visceralistas y sus amantes en Los detectives salvajes.

Palabras clave: Roberto Bolaño, “anarquía erótica”, Los detectives salvajes.

$1 \quad$ Proyecto Postdoctorado 2012 núm. 3120104: "Las mil formas de Venus en la narrativa hispanoamericana contemporánea”, financiado por el Fondo Nacional de Ciencia y Tecnología, Fondecyt. Investigador Responsable: Iván Alexis Candia Cáceres. 
This article proposes the study of the manifestations and meanings of eroticism in The Savage Detectives. Roberto Bolaño's novel can be read from an "erotic anarchy" that is a ritualized exploration of pleasure and, in this sense, is divorced from any connection with reproduction. For Bolaño, eros is a force that liberalizes men and women, transgressing cultural and economic patterns of hegemonic discourses. Thence the intense, varied and disruptive erotic wandering real visceralistas poets and lovers in The Savage Detectives.

KEY WORDS: Roberto Bolaño, “erotic anarchy”, The Savage Detectives.

"Las mil formas de Venus" es una traducción al español de la frase latina "Mille Modi Veneris" de Ovidio, frase citada en uno de los fragmentos de la segunda parte de Los detectives salvajes, que alude no solo a las variadas manifestaciones del sentimiento amoroso sino, también, a las numerosas formas de escenificar físicamente el erotismo. El erotismo es una de las energías más poderosas que corren por el universo de Roberto Bolaño, constituyendo una llamarada que entra en Amberes y que permanece hasta 2666 y que, por cierto, alcanza su máximo ardor en Los detectives salvajes.

La alusión a la frase de Ovidio resulta interesante en la medida en que Los detectives salvajes adopta la propuesta del autor de El arte de amar, es decir, plasma un mundo donde Arturo Belano, Ulises Lima, María Font, Piel Divina, Luis Sebastián Rosado, entre muchos otros, disponen de total libertad para experimentar el placer en sus más diversas dimensiones, lo que los pone, en muchas ocasiones, a contrapelo de las tendencias culturales y sociales que imperan en el mundo reflejado por la novela.

Los detectives salvajes narra el trayecto vital de los poetas visceralistas Arturo Belano y Ulises Lima a partir del diario de vida redactado por Juan García Madero y de los testimonios de diversos personajes que mantienen contacto o relaciones con los líderes del movimiento poético mexicano. La odisea real visceralista está marcada por la búsqueda de la poesía, el sentido épico, la presencia de un sentido dionisíaco y, sobre todo, por la presencia de una "anarquía erótica" que corre como un caballo salvaje en la novela. Abordar los alcances y los sentidos que tiene esa "anarquía erótica" en Los detectives salvajes es el objetivo central de este artículo.

La crítica literaria ha subrayado el rol preponderante del erotismo en el proyecto escritural de Bolaño. Julia Elena Rial destaca esa tendencia de la narrativa bolañiana, en la que aparece "un sexo sodomizado, prehistórico, el cual integra el lenguaje al juego de la transgresión sexual y crea un ambiente donde la violencia resulta indispensable" (Rial). Chiara Bolognese 
sostiene, en tanto, que los personajes de la literatura de Bolaño suelen ser hombres y mujeres que no quieren comprometerse en relaciones estables y, sin embargo, a menudo buscan maneras de entablar vínculos afectivos que les permitan escaparse de su angustia existencial. Así, plantea que el frágil individuo bolañiano a menudo acaba por buscar en la satisfacción sexual sin más compromiso una forma momentánea de llenar la soledad: "Allí (en Los detectives salvajes) el encuentro con el otro no se orienta al descubrimiento de éste, sino más bien a la indagación de sí mismo y a una satisfacción de sus exigencias personales" (Bolognese 228).

Los detectives salvajes puede ser leído a partir de la presencia de una "anarquía erótica" que no solo explica el intenso vagabundeo sexual de los personajes que cruzan la novela sino que muestra, también, el sentido que alcanza el eros en el texto. Hay varios antecedentes que permiten vincular la anarquía con el amor y el erotismo. En Una historia natural del amor Diane Ackerman sostiene que "El amor es anárquico, caótico y emocional" (Ackerman 60). Francesco Alberoni menciona la noción de "anarquía erótica" para explicar el intercambio de parejas propio del jet set: "El star system adoptó ese modelo para que el público [...] aceptara como moral la anarquía erótica del mundo del espectáculo. Es la apariencia formal de aquello que de por sí hubiera sido promiscuidad" (Alberoni 113). Ahora bien, me interesa distinguir la "anarquía erótica" de la simple promiscuidad mencionada por Alberoni -quien no se extiende más allá en las posibilidades de la noción-y, en consecuencia, llenar de significado un concepto que interpreta uno de los lineamientos fundamentales de la novela de Bolaño. Así, es clave abordar primero algunas nociones acerca del erotismo y luego ciertas apreciaciones sobre la anarquía.

Hay varias perspectivas para mirar el fenómeno erótico. Francesco Alberoni sostiene que el erotismo es una forma de interés por otras personas: "Es generosidad intelectual y emocional, capacidad de darse, de dedicarse y abandonarse. El gran erotismo es lo opuesto a la avaricia, la mezquindad y la prudencia" (Alberoni 261). Diane Ackerman afirma que el erotismo permite, en tanto, que hombres y mujeres se liberen de su propio cuerpo: "es una forma de volar desnudos por el espacio..., perdemos el contacto con lo cotidiano, soltamos todas las amarras, y nos desvinculamos de toda conexión con la tierra y la realidad" (Ackerman 286). Para Jeffrey Weeks el erotismo se relaciona más bien con las palabras, las imágenes, el ritual y la fantasía. De ahí que Weeks sostenga que nuestra manera de pensar el sexo modela nuestra manera de vivirlo y gozarlo, "le otorgamos una importancia primordial 
en nuestra vida individual y social debido a una historia que ha asignado un significado central a lo sexual" (Weeks 20). Octavio Paz concuerda con Weeks en el carácter representacional del erotismo. De hecho sostiene que el erotismo no es mera sexualidad animal sino ceremonia, representación. En suma, cree que el erotismo es sexualidad transfigurada: metáfora.

el erotismo es exclusivamente humano: es sexualidad socializada y transfigurada por la imaginación y la voluntad de los hombres. La primera nota que diferencia al erotismo de la sexualidad es la infinita variedad de formas en que se manifiesta, en todas las épocas y en todas las tierras. El erotismo es invención, variación incesante (Paz 15).

A los ojos de Octavio Paz, la imaginación y el ritual transfiguran la sexualidad en erotismo. No puedo sino estar de acuerdo con la afirmación del ensayista mexicano. El erotismo está, en efecto, marcado por la presencia de representaciones y recreaciones que manifiestan múltiples formas de entender y experimentar el eros. Por otra parte, Lamadrid y Muñoz consideran que el significado primario del erotismo humano está centrado en la posibilidad de encontrar placer. Georges Bataille pone el acento, en tanto, en la noción de transgresión asociada con el erotismo. Reich y Marcuse asumen, a su vez, el vínculo que se establece entre erotismo y rebelión, entre erotismo y ruptura, entre erotismo y liberación. En suma, no es posible concebir el erotismo sino como un grito de libertad, un grito que tiene, por cierto, numerosos ecos en Los detectives salvajes.

El anarquismo es una doctrina que aboga por la abolición de la autoridad del Estado y que fomenta la libertad del individuo a través de la supresión de la propiedad privada de los bienes de producción. William Godwin, Pierre-Joseph Proudhon, Piotr Alekséyevich Kropotkin y Mijail Bakunin son algunos de los teóricos que contribuyeron a enriquecer las reflexiones sobre la inconveniencia del Estado. Entre las diversas propuestas teóricas que abordan la anarquía me interesa, particularmente, la visión que ofrece Mijail Bakunin en Estatismo y anarquía debido a que homologa las nociones de anarquía y libertad. Desde una perspectiva eminentemente política, Bakunin afirma que la anarquía consiste en la liberalización de las masas laboriosas frente a la opresión generada por el Estado:

les hemos hecho confesar que la libertad o la anarquía, es decir, la organización libre de las masas laboriosas de abajo a arriba, es el objetivo final del desenvolvimiento social y que todo Estado, sin 
exceptuar su Estado popular, es un yugo que, por una parte, engendra el despotismo y, por la otra, la esclavitud (Bakunin 211).

Bakunin aboga por una anarquía capaz de producir la liberalización de los grupos obreros. Precisamente, esa idea es la que me interesa rescatar de las propuestas de Estatismo y anarquía en la medida en que la liberalización constituye una de las piedras angulares de Los detectives salvajes. Si Bakunin establece que la anarquía es una liberalización frente al poder del Estado, la "anarquía erótica" asume una postura análoga frente a los límites económicos, políticos y culturales que, históricamente, se han establecido frente al reino de Venus.

La "anarquía erótica" tiene que ver con la exploración ritualizada de las posibilidades del cuerpo que apunta a disfrutar de las delicias de la piel, desligando al eros de cualquier clase de vínculo con la reproducción. De esta forma, la "anarquía erótica" apunta a explotar el placer de la carne trascendiendo los límites de una cotidianeidad marcada por la necesidad creciente de aumentar la producción de bienes y servicios en sociedades capitalistas donde impera la determinación de maximizar el rendimiento del cuerpo. Así, se despliega un erotismo que liberaliza los cuerpos de la lógica economicista de las sociedades contemporáneas. Asimismo, la "anarquía erótica" transgrede los interdictos culturales que intentan restringir la actividad erótica. De ahí que esta clase de erotismo asuma una actitud transgresora en la forma de vivir y experimentar las posibilidades que ofrece el cuerpo. Por otra parte, cabe destacar que la "anarquía erótica" encuentra su máxima expresión en la brutalidad, al escenificar la voluptuosidad a partir de la violencia y la crueldad como sellos de un rito que tiende hacia el exceso y el quiebre de los cánones morales y culturales de parte importante de la sociedad occidental.

\section{VENUS LIBERTINA: HACIA UNA “ANARQUÍA ERÓTICA”}

Los detectives salvajes construye una filosofía y una estética de tocador que asume un erotismo abierto a explorar las múltiples facetas de la carne. Aunque en ciertas ocasiones Bolaño se limita a mencionar las relaciones entre los amantes, la mayoría de las veces se sumerge bajo las sábanas y da a conocer las formas y los movimientos de los cuerpos y las sensaciones que experimentan por el vértigo de la piel. Para Bolaño, el erotismo se relaciona con la exploración de las delicias y la fusión de los cuerpos, exploración que tiende a transgredir las convenciones de los grupos de poder. Georges 
Bataille aborda la presencia de la transgresión en el vínculo erótico, cruzando el poder germinativo del eros con la violencia de tánatos. Para Bataille, el erotismo se vincula con la agonía y el padecimiento propio del fin de la vida, no por nada numerosas culturas denominan como "muerte chiquitita" al punto de explosión del erotismo, el orgasmo, "el erotismo es la aprobación de la vida hasta en la muerte" (Bataille 15). Bolaño erige al erotismo como uno de los elementos que simbolizan el ímpetu de la vida que debate el dominio que ejerce el mal, el mercado y el poder en diversos puntos del hemisferio occidental. Jeffrey Weeks adopta una posición similar a la del teórico francés al sostener que el erotismo es "una fuerza proteica, que nace de los recursos del cuerpo y provee energía a las múltiples manifestaciones del deseo" (Weeks 20).

Los detectives salvajes están marcados a fuego por el sentido de la transgresión. De hecho, los real visceralistas realizan un viaje por las variadas posibilidades del erotismo y, en consecuencia, quiebran el tabú. Las mujeres y los hombres que deambulan por Los detectives salvajes, una vez consumidos en el deseo, se convierten en seres desbocados que se abren a toda clase de experiencias. De esta forma, es dable palpar como Arturo Belano, María Font o Simone Darrieux, entre otros, se suman en las caricias de otros cuerpos y otras texturas, superando, en muchas ocasiones, los cánones establecidos respecto del eros.

Roberto Bolaño da forma a un erotismo rupturista que, inequívocamente, se conecta con la dinámica que se produce entre las nociones de transgresión y prohibición desarrollada en El erotismo por Georges Bataille. Para el autor francés, la transgresión tiene que ver con la voluntad del ser humano de exceder los límites. Bajo esta mirada, el hombre desea experimentar el horror que significa acceder al exceso; los hombres están sometidos a un impulso de terror que, por una parte, produce un movimiento de rechazo y, por otra, un impulso de atracción que genera fascinación: "La prohibición y la transgresión responden a esos dos movimientos contradictorios: la prohibición rechaza la transgresión, y la fascinación la introduce" (Bataille 72). Las prohibiciones de las sociedades arcaicas tienen que ver con el erotismo o la muerte. Principalmente, porque las sociedades arcaicas consideran que el erotismo y la muerte son responsables de la violencia. En esta línea, es importante subrayar que la transgresión no es la negación de lo prohibido sino la superación y la complementación de la prohibición. Bataille piensa que existe una prohibición general que cae sobre el erotismo, la que tiene una serie de manifestaciones particulares en las diversas sociedades. Para Bataille, 
el Cristianismo es el responsable de dictaminar los interdictos sexuales en Occidente. Así, legitima una transgresión sancionada (el matrimonio) donde tienen lugar ciertas variantes del erotismo ${ }^{2}$ y deslegitima otras manifestaciones que son calificadas como expresiones de la pecaminosidad.

Aunque las prohibiciones varían en las distintas culturas, existen una serie de tabúes que han trascendido en la civilización occidental. Bajo este prisma, están el interdicto de la sangre menstrual y la sangre del parto, el incesto, las erecciones masculinas y las relaciones sexuales en público. Bataille agrega, por último, la utilización de los conductos prohibidos -especialmente el orificio anal- que, en muchas ocasiones, eran denominados como "las vergüenzas". No por nada San Agustín insistía en lo obsceno de los órganos y la función reproductiva: "Inter faeces et urinam nascimur", vale decir, "Nacemos entre las heces y la orina". En suma, Bataille piensa que sobre las materias fecales cae una prohibición que es el resultado de reglas sociales meticulosas, "análogas a las que cayeron sobre el cadáver o sobre la sangre menstrual. Pero, en conjunto, a través de deslizamientos, se fue formando un ámbito común a la porquería, la corrupción y la sexualidad, elementos cuyas conexiones son muy evidentes" (Bataille 62).

Los detectives salvajes explora un amplio espectro de variables eróticas a lo largo del testimonio de personajes que, por más de veinte años, combaten, sueñan, beben, escriben y, sobre todo, aman como si la vida fuera a terminarse la mañana siguiente. Sin capitulaciones, sin restricciones, sin límites hacen que la transgresión sea un sello de sus estilos de vida. Piel Divina y Luis Sebastián Rosado protagonizan una de las historias eróticas más intensas y complejas de la novela. Mientras Piel Divina es un poeta real visceralista que vive de pequeños "conejeos" (robos) que lo sitúan en las fronteras del lumpenproletariado, Rosado es un discípulo de Paz que se sitúa en el centro de poder cultural de México. Ambos pertenecen, en suma, a mundos opuestos. A la sombra de Romeo y Julieta, Bolaño parece construir una historia de amor imposible. Sin embargo, luego de una encendida velada nocturna en Priapo's y de un encuentro en la cafetería Insurgentes Sur, terminan en el estudio de un amigo de Rosado: "Y yo me dejé arrastrar hasta el baño y me desnudé y abrí la ducha y el chorro de agua fría casi me dejó inconsciente, la carne se

2 El Cristianismo valida las relaciones sexuales que tienen como objetivo primordial la reproducción, excluyendo todas las demás variantes del arte erótico. 
me contrajo hasta sentir cada uno de mis huesos, cerré los ojos, tal vez grité, y entonces él entró en la ducha y me abrazó" (Bolaño 172).

Rosado y Piel Divina mantienen una azarosa relación durante varios años, una relación marcada por la atracción y el deseo de consumar el goce ilimitado de sus cuerpos: "Una noche, mientras me penetraba, le pregunté si alguna vez había matado a alguien. No quería hacerle esa pregunta, no quería oír su respuesta, tanto si era verdad como mentira, y me mordí los labios. Él dijo que sí y redobló sus embites, y yo lloré al correrme" (Bolaño 172). La relación de Rosado y Piel Divina se vincula, a todas luces, con la transgresión de un tabú, tabú que, en la perspectiva de Osvaldo Lamborghini, se relaciona con la tensión que generan "las compuertas del ano". Néstor Perlongher retoma la temática de la analidad puesta en el tapete por Lamborghini, sosteniendo que existe todo un problema con el uso del ano que tiene que ver con el tratado de higiene que existe sobre los cuerpos, el cual se relaciona con la necesidad de sujetar a la civilización. Para Perlongher, sujetar el culo es, en este sentido, una forma de retener y contener a la sociedad occidental. De ahí que vincule su visión de la privatización del ano con la postura que mantienen Deleuze y Guattari en el Antiedipo, interdicto que apunta a instaurar el poder de la cabeza (logo-ego-céntrico) sobre el cuerpo y que está condicionada por un miedo ancestral al "contacto del semen con la mierda, de la perla gomosa de la vida con la abyección fecal" (Perlongher 37).

En Prosa plebeya, Perlongher establece la norma que regula el uso del ano: "Cierta organización del organismo, jerárquica e histórica, destina el ano a la exclusiva función de la excreción - y no al goce. La obsesión occidental por los usos del culo tiene olor a quemado, recuérdese el sacrificio (¿previo empalamiento?) de los sodomitas descubiertos por el ojo de Dios" (Perlongher 37). Perlongher alude a la destrucción de Sodoma y Gomorra por parte del dios del Antiguo Testamento, actitud que responde a las prácticas sodomitas llevadas a cabo por sus habitantes. A partir de ese punto, la teología establece la prohibición y la proscripción de la homosexualidad, posición condenatoria que, posteriormente, será retomada por la medicina: "como ciencia y verdad de los cuerpos ha de modificar el tratamiento, pasando por ejemplo del fuego a la inyección, no por desinfectarse la histeria de sutura amenguará el picor de su insistencia, envuelta en fino, transparente látex" (Perlongher 37). La persecución de la homosexualidad se vincula, en suma, con la utilización libidinal del ano: 
Y si esa obsesión anal, liga o ligamen en el lingam, pareció ante el avance de la nueva "identidad" homosexual, disiparse, es porque esta última modalidad de subjetivación desplaza hacia una relación "persona a persona" (gay/gay) lo que es, en las pasiones marginales de la loca y el chongo, del sexo vagabundo en los baldíos, básicamente una relación "órgano a órgano": pene/culo, ano/boca, lengua/verga, según una dinámica del encaje; esto entra aquí, esto se encaja allí (Perlongher 38).

Rosado y Piel Divina se sitúan en esa última modalidad de subjetivación planteada por Perlongher, produciendo una relación pene/ano que los conecta y que les permite mantener un vínculo que persigue satisfacer el deseo sexual restringido por una sociedad que, mayoritariamente, rechaza la homosexualidad. La erótica de Rosado y Piel Divina resulta atractiva, además, en la medida en que la homosexualidad masculina podría configurarse, en opinión de Félix Guattari en La revolución molecular, en un punto privilegiado de ruptura en el orden social, susceptible de abrirse a un devenir mujer, plataforma de todos los devenires. En suma, sus prácticas sexuales atentan contra el orden social transgrediendo una norma clave del funcionamiento de Occidente.

A partir de la mirada de Bataille, es posible incluir como parte del erotismo transgresor el "reventón de mamadas" protagonizado por el proxeneta Alberto y una prostituta en Azcapotzalco. Luego de contemplar la marcha triunfal de felaciones de la meretriz local, el "chulo" de Lupe se levanta y desafía a la campeona de Azcapotzalco:

Alberto se plantó en medio de la pista, se sacó el vergajo, lo puso en acción con un par de golpecitos y se lo metió en la boca a la campeona. Ésta era dura de verdad y le hizo esfuerzo. Poquito a poquito empezó a tragarse la verga entre las exclamaciones de asombro. Entonces Alberto la cogió de las orejas y se la metió entera [...] En los primeros segundos la ruca pareció que aguantaba, pero luego se atragantó y empezó a ahogarse (Bolaño 50).

La transgresión de los límites constituye un estímulo para el desarrollo del erotismo en Los detectives salvajes. Hay varios episodios donde los real visceralistas se ven excitados ante la posibilidad de quebrar diferentes convenciones sociales. Creo que esta sensación se explica porque la infracción de las normas puede replegar el erotismo a lo vergonzoso y lo sucio. De hecho, Bataille cree que en la transgresión se experimenta una sensación de angustia sin la cual no existiría lo prohibido: la experiencia del pecado. 
La experiencia conduce a la transgresión acabada, a la transgresión lograda que, manteniendo lo prohibido como tal, lo mantiene para gozar de él. La experiencia interior del erotismo requiere de quien la realiza una sensibilidad no menor a la angustia que funda lo prohibido, que al deseo que lleva a infringir la prohibición (Bataille 43).

La sensación de ruptura se levanta como un afrodisíaco. No creo que esto se relacione en la novela con una ofensa religiosa, dado que la religiosidad no juega un papel relevante en Los detectives salvajes, sino más bien con el sentimiento de libertad que acrecienta la plenitud del placer sexual. Así, Bataille piensa que, en ciertas ocasiones, es necesaria una situación escabrosa para acceder al goce carnal.

Aunque son numerosos los episodios de Los detectives salvajes que pueden situarse bajo esta óptica, pienso que existe un capítulo muy significativo respecto de la pasión que provoca la transgresión: la noche que comparten Simone Darrieux y Arturo Belano a mediados de la década de 1970. Simone es una estudiante francesa de antropología que realiza una estadía de investigación en el DF y a la que le gusta practicar el sadomasoquismo. Belano es el líder de los vicerrealistas. Luego de mantener una amistad por más de un año, una noche, deciden irse a la cama. Durante mucho tiempo, Belano besa y acaricia a Simone, pero no logra una erección. Todo parece conducir al fracaso. Sin embargo, la situación da un giro sorpresivo:

y en ese momento, no sé por qué, a mí se me ocurrió decirle que se metiera a la cama, que se pusiera encima de mí y que me diera golpecitos en las mejillas o en el culo, y él me miró y dijo yo soy incapaz de hacer eso, Simone, y luego se corrigió y dijo: también soy incapaz de eso, Simone, pero yo le dije venga, valor, métete en la cama, y él se metió, me di la vuelta y levanté las nalgas y le dije: empieza a pegarme poco a poco, haz cuenta de que esto es un juego, y él me dio mi primer azote y yo hundí la cabeza en la cama, no he leído a Rigaut, le dije, ni a Max Jacob, ni a los pesados de Banville, Baudelaire [...] pero sí que he leído al Marqués de Sade. ¿Ah, sí? dijo él. Si, dije yo, acariciándole la verga. Los golpes en el culo cada vez los daba con mayor convicción. ¿Qué has leído del Marqués de Sade? La filosofía en el tocador, dije yo [...] ¿Y Los 120 días de Sodoma? Claro que sí. Para entonces estaba húmeda y gimiendo y la verga de Arturo enhiesta como un palo, así que me volví, me abrí de piernas y le dije que me la metiera, pero que sólo hiciera eso, que no se moviera hasta que yo se lo dijera. Fue rico sentirlo dentro 
de mí. Abofetéame, le dije. En la cara, en las mejillas. [...] Él me abofeteó. ¡Más fuerte!, le dije. Él me abofeteó más fuerte. Ahora, empieza a moverte, le dije. Durante unos segundos en la habitación sólo se escucharon mis gemidos y los golpes. Después él también se puso a gemir. Hicimos el amor hasta que amaneció (Bolaño 226).

Las variantes tradicionales de los juegos eróticos no parecen estimular a Simone ni a Arturo. La sensación de romper los límites y de cruzar las fronteras de lo prohibido, no obstante, lleva a la pareja no solo a disfrutar de sus cuerpos sino a concretar una relación que, por un momento, parecía no llevar a nada más que a una silente frustración. Sin embargo, la transgresión actúa como un poderoso estímulo para los amantes.

Bajo esta perspectiva, creo que no solo es posible sino también necesario leer el erotismo de Los detectives salvajes desde la dinámica transgresión/ interdicto propuesta por Bataille. No se puede soslayar, sin embargo, que El erotismo fue publicado en 1957, período en el que el Cristianismo tenía una influencia superior a la que posee actualmente en Occidente y en el que, por cierto, las sociedades desarrolladas -para qué decir los países subdesarrollados- eran mucho más conservadoras que a inicios del siglo XXI. Es más, El erotismo aparece antes de la irrupción de los movimientos liberales -mujeres, homosexuales- de las décadas de 1960 y 1970. De esta forma, resulta fundamental preguntarse si todavía son válidas las prohibiciones sugeridas por el teórico francés o si éstas se han diluido con el paso del tiempo. Creo que hay dos líneas de pensamiento para resolver este problema.

En El malestar en la sexualidad. Significados, mitos y sexualidades modernas, Jeffrey Weeks sostiene que la evolución tecnológica del capitalismo y sus constantes innovaciones de los métodos de control de la natalidad produjeron la separación entre erotismo y procreación. En la medida en que la búsqueda del placer se convirtió en un fin en sí mismo, piensa Weeks, se "allanó el camino para la proliferación de nuevos deseos" (Weeks 51). La ruptura del vínculo sexo-procreación constituye un fenómeno potencialmente liberador. Anthony Giddens sostiene, también, que se ha producido una profunda transformación de la intimidad en Occidente desde el siglo XIX. Para Giddens, el primer elemento fundamental en este proceso es la tendencia a limitar el tamaño familiar debido a que, lejos de ser una estadística demográfica, implica que el erotismo puede separarse del ciclo crónico de embarazo y parto, el que, en muchas ocasiones, podía acabar en la muerte de la madre. Luego de la Primera Guerra Mundial comienzan a cobrar importancia los 
métodos modernos de contracepción, los que se consolidan a mediados del siglo pasado. Precisamente, son estos métodos los que permiten separar el erotismo de la reproducción: "Con la elaboración ulterior de las tecnologías reproductivas, esta diferenciación se ha hecho completa. Hoy esta concepción puede ser artificialmente producida, en lugar de ser artificialmente inhibida. La sexualidad es al fin plenamente autónoma" (Giddens 36).

Lo anterior implica una liberación final de la sexualidad, la que se convierte en una cualidad de los individuos y de sus transacciones con los demás. Así, el erotismo adquiere como objetivo central la búsqueda del placer. Para Giddens, la "revolución sexual" que se produce a partir de la década de 1960 implica dos elementos que modifican la intimidad de las sociedades desarrolladas:

\begin{abstract}
uno es la revolución en la autonomía sexual femenina [...] El segundo elemento es el florecimiento de la homosexualidad, masculina y femenina. Los homosexuales de ambos sexos han establecido una nueva base sexual que sobrepasa con mucho lo más ortodoxo desde el punto de vista sexual (Giddens 36).
\end{abstract}

De esta forma, Giddens establece que se origina una "sexualidad plástica" que resulta crucial para la reivindicación del placer sexual por parte de las mujeres. Giddens sostiene que la sexualidad plástica es una sexualidad descentrada, liberada de necesidades de la reproducción, "tiene sus orígenes en la tendencia iniciada a finales del siglo XVIII, a limitar estrictamente el número familiar; pero se desarrolla posteriormente, como resultado de la difusión de la moderna contracepción" (Giddens 12). La creación de una "sexualidad plástica", separada de la reproducción, fue la condición previa de la revolución sexual de las pasadas décadas.

Desde esta perspectiva, la dinámica intedicto-prohibición de Bataille se vería desacreditada por la irrupción de una nueva forma de entender la intimidad, dado que se reduciría el ámbito sobre el cual se pueden extender los tabúes. Ni la utilización de los conductos prohibidos, ni la masturbación, ni el sexo en público ${ }^{3}$ serían considerados como interdictos. Tal vez solo el incesto podría seguir manteniendo la condición de tabú. En este sentido, la prohibición general que se extiende sobre el erotismo se ha debilitado en los

\footnotetext{
Pienso en los numerosos espacios públicos que se abren a partir de la década de 1960 para sostener sexo en público, tales como saunas, lugares de intercambios de parejas, entre otros.
} 
últimos cincuenta años. Ahora bien, cuando hablo de sociedad occidental me refiero a como el común de la gente disfruta de esta nueva forma de sentir el eros.

Los detectives salvajes se hace cargo de ese profundo cambio experimentado por el erotismo, que aparece como una fuerza irreducible que consume a los personajes y los lleva a seducir a los sujetos/objetos del deseo para catartizar -aunque sea parcialmente- la fuerza que parece devorarlos. Ambientada a lo largo del siglo XX, Los detectives salvajes relata la vida de mujeres que, ayudadas por la progresiva irrupción de los métodos de contracepción, desligan su erotismo de la reproducción y fijan su interés sexual en la obtención del placer. Lejos de cualquier actitud pasiva e incluso indiferente frente al sexo, procuran vivir un erotismo intenso, procurándose el máximo goce en los intermitentes y/o permanentes contactos sexuales que mantienen con hombres y, en el menor de los casos, mujeres. Lejos de mantener una sola pareja en su vida y de concentrarse en el cuidado de los hijos, Auxilio Lacouture, Angélica y María Font, Edith Oster, por nombrar algunas, tienen numerosos amantes durante sus vidas con los que pueden establecer o no vínculos sentimentales, pero con los que el punto de unión pasa por el deseo de disfrutar de las delicias del cuerpo. Para profundizar esta directriz me interesa analizar a María Font.

La diosa Venus parece dar un extenso y penetrante paseo por Los detectives salvajes, el que, aparentemente, la lleva a encarnar en una serie de mujeres que dan rienda suelta a la voluptuosidad que corre por sus venas. María Font, poeta realvisceralista nacida en la década de 1950, es parte de la primera generación que recibe y recoge la liberalización sexual de los sesentas. María Font es, en cierta forma, la ninfa del realismo visceral, fuente de deseo de García Madero, Piel Divina, Jacinto Requena y Moctezuma Rodríguez, todos los que experimentan con las pasiones y los deseos de la asidua lectora de Sor Juana Inés de la Cruz y del Marqués de Sade, tal como pone de manifiesto la iniciación sexual de García Madero:

Por el aliento supe que estaba a pocos milímetros del rostro de María [...] su mano [...] me bajó la cremallera de mis pantalones y buscó mi verga [...] Exploré el cuerpo desnudo de María, el glorioso cuerpo desnudo de María en un silencio contenido, aunque de buena gana hubiera gritado, celebrado cada rincón, cada espacio terso e interminable que encontraba. María, menos recatada que yo, al cabo de poco comenzó a gemir y sus maniobras, inicialmente tímidas o mesuradas, fueron haciéndose más abiertas $[. .$.$] Después [\ldots]$ me 
monté encima y se lo metí [...] Miré a ambos lados de la cama mientras las piernas de María se anudaban y desanudaban sobre mi espalda (Bolaño 64-65).

María no solo toma la iniciativa ante el inexperimentado García Madero sino que es la responsable de dirigir sus movimientos con el objetivo de alcanzar el placer. Su actitud no varía con una pareja más experimentada. María mantiene el control de las explosiones del erotismo, tal como señala, por ejemplo, Piel Divina, "es lo gacho de María, las cosas con ella son fuertes pero tienen que ser a su manera" (Bolaño 74). Luego de su desvinculación del real visceralismo, María sigue teniendo esporádicos amantes, mas nada cambia, la mayor de las hermanas Font sigue teniendo las riendas de su erotismo salvaje.

Acorde a los parámetros sugeridos por Giddens y Weeks, Bolaño abre su narrativa hacia varias manifestaciones sexuales distintas a la heterosexualidad tradicional, tales como a la homosexualidad, la bisexualidad y el sadomasoquismo. Para este punto, me interesa concentrarme en el rol que desempeña el poeta realvisceralista Ernesto San Epifanio. San Epifanio es un símbolo de la libertad homosexual de la década del setenta del siglo pasado, pues vive disipadas y numerosas aventuras eróticas con hombres de la más variada especie. De ahí que pueda involucrarse con otros escritores, con jóvenes ricos o con individuos cuyas actividades están en los límites de la ley o que son, derechamente, parte del hampa. Una de las aventuras de San Epifanio tiene que ver con la relación erótico-amorosa que mantiene con el hijo del embajador de Honduras, con quien incluso llega a producir pornografía. San Epifanio realiza con su amante y con la hermana de éste más de sesenta fotografías. Aunque Weeks sostiene que existen diversas perspectivas desde donde mirar la pornografía, me interesa particularmente la mirada de los liberales en la medida en que es la que coincide en mayor grado con la narrativa de Bolaño. Weeks establece, en este sentido, que: "la pornografía es una fiesta móvil, el producto de un cambio en la interpretación de lo que es el buen gusto y la pertinencia" (Weeks 368). La secuencia fotográfica incluye imágenes sexuales explícitas:

Aproximadamente por la foto número veinte el muchacho rubio comenzaba a vestirse con la ropa de su hermana [...] Las fotos siguientes mostraban a San Epifanio besando el cuello del adolescente rubio, sus ojos, su espalda, su verga a media asta, su verga enhiesta $[\ldots]$ bajo la siempre atenta mirada de la hermana $[\ldots]$ las siguientes 
fotos mostraban al lector de Bryan Patten enculando al adolescente rubio [...] El rostro del muchacho enculado se retorcía en una mueca que presumí de placer y de dolor mezclados (Bolaño 58).

Ahora bien, retomando la temática de la transgresión, creo que es dable sostener que Los detectives salvajes se hace cargo de esta modernización de la intimidad de la sociedad occidental y, en este sentido, perdería fuerza la postura de Bataille. Sin embargo, queda todavía una interrogante que es necesario dilucidar. Cabe precisar si las transformaciones de la intimidad afectan a los discursos hegemónicos.

Homi Bhabha considera que la nación resulta de la tensión entre una zona de poder y un área liminal o subalterna, es decir, entre el sector social que detenta la fuerza económica, política, y militar, y la otra fracción que es forzada a adoptar una posición de sometimiento frente al primero y que se sitúa en los márgenes de la sociedad. La primera propugna un discurso monológico frente al discurso heteroglósico defendido por la segunda. De esta forma, la nación: "representa el borde entre los poderes totalizantes de lo 'social' como comunidad homogénea y consensual, y las fuerzas que significan la interpelación más específica a intereses e identidades contenciosos y desiguales dentro de la población" (Bhabha 182). Las reflexiones de Bhabha son útiles por cuanto establecen la presencia de dos áreas que están en una constante disputa del poder a través del discurso. El erotismo no escapa a esta lógica. También, es motivo de la creación y la difusión de un discurso que genera pautas de cómo se debe entender y/o vivir la sexualidad. Probablemente, uno de los mayores aportes en este sentido proviene de Michel Foucault, quien en Historia de la Sexualidad. La voluntad de saber, establece que el erotismo es el dominio del otro a partir del cruce de sexualidad, saber y poder. Para Foucault, existen estrategias que buscan establecer relaciones de fuerza, cuya cristalización institucional toma forma en los aparatos estatales, en la formulación de la ley y en las hegemonías sociales. Foucault distingue cuatro conjuntos estratégicos que se despliegan de los dispositivos de saber y de poder: Histerización del cuerpo de la mujer, Pedagogización del sexo del niño, Socialización de las conductas procreadoras, Psiquiatrización del placer perverso. Para Foucault, la cárcel, el manicomio y la escuela son las instituciones encargadas de controlar las anomalías sociales y de aplicar la "buena violencia social".

Michel Foucault sostiene que la sociedad genera una serie de estrategias represivas sobre las manifestaciones de la sexualidad que no sean funcionales 
al desarrollo social y económico de la nación. Desde una perspectiva historiográfica, Francisco Vidal concuerda con la perspectiva del teórico francés, pero precisa que la Iglesia Católica en acomodo con la ciencia particularmente con la medicina- estableció desde el siglo XIX una actitud condenatoria y punitiva hacia la sexualidad, "la masturbación se considera lesiva para el cerebro y para el sistema nervioso central, la homosexualidad se entiende como patología y a la mujer no se la concibe como capaz de respuesta sexual" (Vidal 28). Para López y Fuertes, en tanto, la ciencia se limitaba a legitimar lo que afirmaban los moralistas: "Estaban convencidos que existía una perfecta coincidencia entre la moral y los criterios educativos y clínicos. $\mathrm{Si}$ algo era considerado por la moral como inadecuado, los profesionales lo catalogaban como desviado o patológico" (cit. en Vidal 28). En "Sexualidad y modernidad en Chile: una relación espúrea", Vidal establece que el último cuarto del siglo XIX estuvo marcado por las ideas del psiquiatra Richard von Krafft-Ebing -autor influenciado por la moral victoriana- quien establece una pormenorizada clasificación de las disfunciones y perversiones sexuales, dentro de las que destacan el sadomasoquismo, la homosexualidad y la masturbación. De este modo, la sexualidad entra al campo de estudio de la medicina, pero lo hace a través de la patología.

Para Vidal, este discurso pierde fuerza en el siglo XX. Así, el médico inglés Havelock Ellis relativiza el concepto de normalidad y rechaza muchos tópicos considerados como verdades científicas. La masturbación deja de conceptualizarse como una conducta degenerativa, pasando a ser caracterizada como una práctica común en ambos sexos; la homosexualidad se entiende como una conducta minoritaria y no como una desviación y el placer es considerado deseable tanto para el hombre como para la mujer. De esta forma, Ellis le imprime una connotación positiva a la sexualidad.

Francisco Vidal piensa que una vez que se debilita la alianza entre la medicina y la religión católica, vale decir, cuando la medicina deja de avalar la relación entre pecado y enfermedad, los defensores de la fe católica encuentran un nuevo y poderoso aliado en los sectores de la derecha política, "junto con su influencia en el ámbito de la política, desempeñan el principal papel en el funcionamiento del sistema económico neoliberal, con sus subsecuentes ramificaciones en el campo educativo y en el manejo de los medios de comunicación" (Vidal 40). Para Vidal, esta alianza de la Iglesia Católica y los sectores de derecha ha impuesto una serie de restricciones y limitaciones a los medios de comunicación social para hablar del tema de la sexualidad. 
Los aportes de Vidal son claves para determinar la utilidad de la dinámica transgresión/interdicto en el análisis de Los detectives salvajes, pues establecen que si bien es innegable que se han producido profundas modificaciones en la intimidad de los latinoamericanos, sigue teniendo fuerza un discurso dominante que tiende a reprimir las manifestaciones más liberales del erotismo. De esta forma, la transgresión sigue teniendo vigencia en cuanto se considere que el marco de control que la determina está representado por un discurso que intenta controlar los avances del erotismo en Latinoamérica.

La presencia de este discurso evoca la hipótesis represiva de Sigmund Freud en El malestar de la cultura. En este texto, Freud sostiene que la función de la cultura es remediar el sufrimiento del hombre a través de las instituciones que la materializan, sin embargo, en la medida en que estas instituciones ponen límites a la búsqueda del placer, la cultura se transforma en una nueva causa de sufrimiento. Freud sugiere que el hombre y la mujer se encuentran en un dilema: tienen necesidad de los otros, pero sueñan con vivir a distancia de esa sociedad que limita sus pulsiones sexuales. Así, la elección de objeto sexual queda restringida al individuo sexualmente maduro del sexo contrario y la mayor parte de las satisfacciones extragenitales son prohibidas como perversiones. La cultura actual nos da a entender que solo está dispuesta a tolerar las relaciones sexuales basadas en la unión única e indisoluble entre un hombre y una mujer, sin admitir el erotismo como fuente de placer en sí y aceptándola tan solo como instrumento de reproducción humana. La cultura obliga a los hombres a restringir la libido y a orientarla a un individuo del sexo contrario, restringiendo el erotismo al sexo vaginal y excluyendo otras manifestaciones que son consideradas como perversiones.

Frente a los efectos de la hipótesis represiva, se levantan las voces de una serie de teóricos que no están dispuestos a aceptar un erotismo "encarcelado".

Wilhelm Reich concuerda con la tesis central de El malestar en la cultura, esto es, que la existencia de la cultura resulta de una represión originaria de la satisfacción agresiva y erótica. Sin embargo, Reich difiere con Freud no solo en términos de la equiparación freudiana de las instituciones modernas con la civilización en general, sino también con relación a la idea del instinto de muerte en la medida en que la destructividad resulta de la frustración de la libido. Para Reich, la posición de Freud debilita la liberación sexual y bloquea las implicaciones más radicales de sus propias ideas, conduciendo a la consolidación del matrimonio burgués. 
La cultura moderna está regida por un poder hegemónico representado por el reino del "hombrecillo" ", dominio en el que se encuentran los orígenes del autoritarismo. Precisamente la neurosis del "hombrecillo" es la que provoca la represión de la energía sexual, la que contribuye a generar una sociedad jerárquica y patriarcal. Bajo esta perspectiva, Reich piensa que es necesario dar curso a la expresión libre de los impulsos eróticos y, además, reconocer los impulsos agresivos. Así, Reich aboga por la igualdad de la expresión sexual de las mujeres, por los derechos de los niños a los juegos sexuales y a la masturbación y, también, por la satisfacción de las necesidades de los adolescentes. En suma, es dable sostener que Reich piensa que es necesario oponer el erotismo al poder. El erotismo es la principal fuente de felicidad del ser humano. Para Reich, todos los que son felices están libres de la sed de poder. Así, Reich cree que el erotismo orientado hacia el abrazo amoroso proporciona una vía más allá del control social, un camino hacia la libertad desde las ataduras del deseo sexual dominado.

Al igual que Freud y Reich, Herbert Marcuse parte también de la idea de un poder simbolizado por una cultura que ejerce una represión básica. Para Marcuse, la represión se ha visto acrecentada en la sociedad moderna por las exigencias de una mayor disciplina económica. Así, los sujetos habrían puesto un excedente a fin de utilizar esa energía en la producción. El individuo, al ajustarse al "principio de la realidad", responde de hecho a las exigencias de una forma de dominación explotadora.

En la óptica de Marcuse, la disciplina del trabajo moderno solo es posible en cuanto el cuerpo sea deserotizado. De esta forma, emerge un cuerpo laborante cuyo erotismo se restringe a su capacidad de reproducción. Sin embargo, Marcuse sostiene que el amor sensual puede resultar liberador en un doble sentido. En primer término, el amor quebranta el marco de la familia patriarcal y monogámica cuando se respeta al otro como un igual. En segundo lugar, el amor es compatible con una ciudadanía social más amplia. De ahí que Marcuse sostenga que liberar al eros es coherente con una verdadera condición política para construir relaciones societarias civilizadas. Por último,

\footnotetext{
El "hombrecillo" es un personaje que Wilhelm Reich desarrolla en Listen, little man! que simboliza el poder de la sociedad burguesa. El "hombrecillo" es un miembro del sexo masculino que detenta ciertas posiciones de poder y que representa la decadencia y la miseria de un orden social que intenta someter al deseo sexual. Para Reich el "hombrecillo" resulta paradójico en términos de que toda su voluntad de control sexual se contrapone a su mente pornográfica y a su perpetua hambre sexual.
} 
resulta necesario consignar que a través de la reerotización del cuerpo, de la renovación del significado del erotismo y de la exploración estética de la sensualidad humana es posible construir una sociedad más plena:

Así, el concepto de una forma de vivir no represiva ha sido invocado [...] para mostrar que la transición a un nuevo estado de civilización, que las posibilidades de la época actual sugiere, puede implicar la subversión de la cultura tradicional, tanto en el aspecto intelectual como en el material, incluyendo la liberación de las necesidades y satisfacciones instintivas que hasta hora han permanecido como tabús y han sido reprimidas (Marcuse 10).

Algunos intelectuales más contemporáneos, como Weeks y Giddens, se encuentran en la misma senda abierta por Reich y Marcuse. Mientras Weeks sostiene que el sexo es la más irreducible de las energías naturales, "rebelde frente a los esfuerzos de la represión, resistente a las modificaciones del clima y de la cultura" (Weeks 39), Giddens propone que el sexo se proyecta siempre en el dominio público y, sobre todo, habla el lenguaje de la revolución: "representa un reino potencial de libertad, no reducido por los límites de la civilización contemporánea" (Giddens 11).

Los detectives salvajes evidencia una "anarquía erótica" que implica en sí misma una manera de vivir y entender el eros. La "anarquía erótica" es la búsqueda inequívoca del fulgor que surge de la expansión del fuego; mujeres y hombres extienden sus manos para embriagarse en sus llamas y alcanzar el placer efímero pero, a su vez, salvaje e intenso, que se encuentra en el cruce de las intimidades. Desligada de cualquier clase de contacto con la reproducción e incluso con el amor, persigue el breve resplandor de goce. Pese a que el amor puede constituir un afrodisíaco y un factor que aglutina el flujo de la pasión, no es un elemento imprescindible en esta forma de entender el eros. Si lo es, en cambio, el deseo de extender la libertad a todas las formas de ver, sentir y vivenciar el juego de los sentidos. De ahí que la "anarquía erótica" se resista a cualquier clase de límite impuesto por los núcleos de poder y que se abra a las tentativas de llevar las delicias del cuerpo hasta el extremo.

La "anarquía erótica" cruza Los detectives salvajes. Creo que es posible apreciarlo en las noches que Arturo Belano y Simone Darrieux pasan copulando en la casa de la francesa, entregándose a disfrutar infatigablemente de sus cuerpos y no mezclando jamás esos encuentros ni con la posibilidad de engendrar ni mucho menos con el amor. Este se hace palpable, también, en los variados contactos sexuales que establece Lupe con García Madero, Quim 
Font o Alberto. La "anarquía erótica" se extiende, además, a las inestables relaciones que Piel Divina mantiene con numerosos hombres y mujeres en México y que sintetiza de la siguiente forma: "Me he acostado con todos los poetas de México" (Bolaño 173).

La "anarquía erótica" pone en escena la "carne", es decir, la convulsión erótica, la experiencia de la violencia en el momento de la explosión. En Los detectives salvajes queda al desnudo ese desequilibrio en que irrumpe la violencia a través de los movimientos animales de esos órganos hinchados de sangre y en el que la voluntad se torna una fuerza evanescente. Bataille realiza una analogía entre el acto del amor y del sacrificio, debido a que ambos revelan lo que llama la "carne". El sacrificio sustituye la vida ordenada del animal por la convulsión ciega de los órganos. Lo mismo sucede con la convulsión erótica: libera unos órganos pletóricos cuyos juegos se realizan a ciegas, más allá de la voluntad reflexiva de los amantes. Una violencia que la razón deja de controlar anima a esos órganos, los hace tender al estallido y súbitamente explota la alegría de los corazones al dejarse llevar por el rebasamiento de ese torbellino:

La carne es en nosotros ese exceso que se opone a la ley de la decencia $[\ldots]$ si, como creo, existe una prohibición vaga y global que se opone, bajo formas que dependen del tiempo y del lugar, a la libertad sexual, entonces la carne es la expresión de un retorno de esa libertad amenazante (Bataille 98).

En los poco más de tres meses que se extiende el diario de Juan García Madero, es decir, desde 2 de noviembre de 1975 hasta el 15 de febrero de $1976^{5}$, asistimos a la radical transfiguración que experimenta su vida sexual, pasando desde su inicial estado "virginal" a las disipadas relaciones sexuales que mantiene -casi de forma simultánea-con Brígida, María, Rosario y Lupe. García Madero experimenta su primera felación en un bar:

Brígida, sin dejar de mirarme, se arrodilló, me abrió la cremallera y se metió la verga en la boca. Primero el glande, al que le propinó

$5 \quad$ No deja de ser interesante que el relato comience inmediatamente después de la conmemoración del día de los muertos y que se termine una vez finalizado el día del amor. Bolaño parece conectar directa o indirectamente a Eros y Thánatos. 
varios mordisquitos que no por leves fueron menos inquietantes y después al pene entero sin dejar de atragantarse (Bolaño 77).

Luego de su primera relación sexual con María, experiencia que constituye una iniciación no solo en términos del comienzo de la vida erótica sino también en cuanto al aprendizaje del arte de amar, García Madero asume una posición activa en la búsqueda del placer de sus parejas, las que progresivamente serán llevadas a los delirios de la "carne":

Rosario estuvo fantástica [...] Se vino quince veces. Las primeras le tenía que tapar la boca para que no despertara a los vecinos. Las últimas temí que le fuera a dar un ataque al corazón. A veces parecía desmayarse entre mis brazos y otras veces se arqueaba como si un fantasma estuviera jugando con su columna vertebral (Bolaño 98).

[...] y le dije a Lupe que me siguiera y nos fuimos a su habitación en donde nos dedicamos a coger como locos o como si nos fuéramos a morir mañana, hasta que se hizo de noche y oímos las voces de Lima y Belano que habían vuelto a su habitación (Bolaño 570).

Para Bataille, la "carne" se traduce no solo en la pérdida de dominio sino, también, en la transformación que afecta la conducta de los hombres y las mujeres. Así, supone la sorpresa que experimentaría una persona ante la transformación de una dama distinguida -si la furia del erotismo no le resultara familiar- en los brazos de su amante. Para Bataille, vería en ello una enfermedad análoga a la rabia canina:

Como si una perra rabiosa hubiese suplantado la personalidad de aquella que recibía a sus visitantes con tanta dignidad... hasta es demasiado poco hablar de enfermedad. Durante esos momentos, la personalidad está muerta; y su muerte, en esos momentos, deja lugar a la perra, que se aprovecha del silencio, de la ausencia de la muerta. La perra goza, y lo hace gritando, de ese silencio y de esa ausencia (Bataille 112).

Ahora bien, estoy convencido de que en Los detectives salvajes suceden una serie de acontecimientos que muestran la muerte de la personalidad y la irrupción de la "rabia canina". Con todo, la imagen más significativa, en este sentido, acaece cuando Xosé Lendoiro, poeta, abogado y dueño de una revista literaria en la que trabaja Arturo Belano, encuentra a su hija en los brazos del poeta real visceralista: 
Entreabrí la puerta y vi a mi hija mayor en brazos de Belano. Lo que éste le hacía me pareció, al menos al primer golpe de vista, inenarrable. La arrastraba por la enorme extensión de mi cama de un lado a otro, se montaba en ella, la daba vueltas, todo en medio de una serie espantosa de gemidos, rugidos, rebuznos, zureos, ruidos obscenos que me pusieron la piel de gallina. Mille modi Veneris, recordé con Ovidio [...] Las imágenes de mi hija comportándose como una perra acudían a mi cabeza en oleadas, y cada oleada me dejaba empapado en sudor (Bolaño 436).

\section{VENUS ENSANGRENTADA: LAS MIL FORMAS DE LA BRUTALIDAD}

Los detectives salvajes presenta distintos momentos en que la "anarquía erótica" alcanza un punto máximo de ebullición, palpando una intensidad extrema que se sitúa en las fronteras de la brutalidad. La brutalidad hace su aparición en la narrativa bolañiana al escenificar la voluptuosidad a partir de un desequilibrio pasional que lleva a explotar las delicias de los cuerpos y que tiene a la violencia y a la crueldad como sellos de un rito que tiende hacia el exceso y el quiebre de los cánones culturales occidentales. La brutalidad busca los límites del placer, apuntando a una liberación y a una revolución frente a las convenciones que rigen la forma de vivir y disfrutar el erotismo en sociedades influenciadas por ingentes aparatos de poder y control ético-cultural.

Los detectives salvajes es la novela de Bolaño que explora con mayor fuerza y profundidad la brutalidad. Abierta a todo el espectro del erotismo, incluye algunos episodios marcados por la violencia que se cuela en las habitaciones bolañianas. Bajo esta óptica, se sitúan las acciones de Simone Darrieux, lectora del Marqués de Sade, que introduce y difunde la práctica de sexo extremo entre los poetas realvisceralistas. Darrieux mantiene una relación con el líder de los visceralistas, Arturo Belano, vínculo que, a partir del acuerdo entre dos personas en igualdad de condiciones, está orientado a realizar las fantasías prohibidas que generan placer en Arturo y Simone. Así, ponen en escena un sexo brutal que los llevan a conseguir una sensación intensificada de liberación y placer: "Fuimos amantes durante un tiempo. Tres meses, exactamente, lo que me faltaba para volver a París. No todas las noches hicimos el amor. No todas las noches nos veíamos. Pero lo hicimos de todas las formas posibles. Me ató, me azotó, me sodomizó" (Bolaño 227). 
Darrieux relata un ritual que constituye un gesto de rebelión y resistencia ante el discurso monológico sobre el erotismo, plasmando una dura puesta en escena que dialoga con una práctica extendida durante el siglo XX: el sadomasoquismo. El sadomasoquismo, considerado como una de las manifestaciones de la sexualidad perversa por Freud, constituye para Marcuse una rebelión contra la norma procreadora, apuntando así a un significado más pleno del Eros, en el que el impulso de vivir representa la realización de todas las posibilidades del cuerpo. El sadomasoquismo (S/M) se ubica en los límites del erotismo aceptable. Jeffrey Weeks sostiene, en este sentido, que la política del S/M se destaca por una subjetividad puesta en el significado de la situación, tal como la ven sus practicantes; y por su énfasis en la elección, en el derecho a involucrarse en situaciones extremas para obtener placer. La subjetividad y la elección se implican mutuamente pues el S/M es válido en situaciones de consenso entre iguales donde la erotización ritualista del deseo de sufrimiento, las diferencias de poder como significantes del deseo y la realización de fantasías prohibidas son vías para alcanzar el placer. El sadomasoquismo se convierte en un teatro del sexo, donde los compañeros consienten realizar actividades extremas que llegan hasta los límites de la resistencia para alcanzar el placer. Para Weeks el sadomasoquismo es el intento más radical, en el campo de la política sexual, de promover simplemente el placer como objetivo fundamental del sexo. El sadomasoquismo es la quintaesencia del sexo no reproductivo:

En el S/M parece importar tanto el ritual, como la zona del cuerpo, la erotización de la situación, tanto como el orgasmo. Todo el cuerpo se convierte en lugar de placer, y el cultivo de roles y prácticas exóticas son la clave para la obtención del placer. En estas prácticas está teniendo lugar una degenitalización del sexo y del placer que rompe nuestras expectativas sobre lo erótico (Weeks 382).

Abiertamente influenciada por las ideas de Darrieux, María Font decide también poner en práctica sus lecturas del Marqués de Sade. De esta forma, experimenta el placer del S/M con su amante Piel Divina, con el cual evidencia que el placer no está limitado a ciertas partes del cuerpo y que, por el contrario, es posible erotizar diversas texturas y cavidades a través del ejercicio de la violencia:

con una mano la golpeaba y con otra le acariciaba el clítoris y las tetas. $[\ldots]$ cada vez le iba dando más fuerte. En las nalgas, en las 
piernas, pero también en el coño. ¿Ustedes lo han hecho así alguna vez, muchachos? Bueno, se los recomiendo. Al principio el sonido, el sonido de las palmadas como que no sale muy bien, te desconcentra, es algo como demasiado crudo en un plato en donde las cosas son más bien cocidas, pero luego como que se acopla a lo que estás haciendo, y los gemidos de ella, los de María, también se acoplan, cada golpe produce un gemido, y eso va in crescendo, y llega un momento en que sientes sus nalgas ardiendo, y las palmas de tus manos también arden, y la verga te empieza a latir como si fuera un corazón, plonc, plonc, plonc, plonc [...] Y ella también latía, le latían las nalgas y las piernas y los labios de la vagina y el clítoris, lo sé porque entre golpe y golpe la acariciaba, le pasaba la mano por ahí y lo notaba y eso me ponía calentísimo y tenía que hacer esfuerzos para no venirme (Bolaño 73-74).

Las prácticas $\mathrm{S} / \mathrm{M}$ de María y Piel Divina son interesantes no solo porque representan un erotismo orientado a la obtención del placer de manera extrema, el que bajo ninguna circunstancia aceptaría la influencia del discurso monológico, sino porque ponen en evidencia cómo el vínculo de poder en el $\mathrm{S} / \mathrm{M}$, lejos de erigirse como el resultado de variables económicas y/o culturales, responde, más bien, a un acuerdo producto de la confianza y la seducción.

\section{VENUS VICTRIX}

Las mil formas de Venus resplandecen en Los detectives salvajes, es decir, estamos ante un texto que se abre hacia las más diversas formas de escenificar el vértigo del cuerpo. El eros en la novela de Bolaño responde a una "anarquía erótica" que, desligada de cualquier clase de contacto con la reproducción, tiende, en primer lugar, a la búsqueda del placer. De ahí que sus personajes experimenten el erotismo vaginal, anal, oral, el sadomasoquismo, entre otras variantes. La "anarquía erótica" apunta, en segundo término, a la libertad de los sentidos y a la revolución de la piel. Así, no acepta ninguna clase de discurso que tienda a restringir, limitar o encausar la voluptuosidad. Para esto, los real visceralistas y sus amantes experimentan un errabundeo sexual que los lleva a degustar distintos sabores de la piel. Asimismo, es dable establecer que la "anarquía erótica" alcanza su máximo nivel cuando Bolaño da curso a la brutalidad, es decir, mediante la radicalización de la violencia y la crueldad en la exploración de los placeres del cuerpo. 
En Los detectives salvajes se levanta una "anarquía erótica" que apuesta a vivir hasta el exceso. La "anarquía erótica" es la erupción del cuerpo que evidencia la fuerza y la capacidad regenerativa de la vida y, en este sentido, la tenue esperanza de que sea posible resistir eróticamente a las exigencias del mercado, el poder y el mal que amenaza, constantemente, a los real vicerrealistas. En suma, la "anarquía erótica" pone en acción uno de los núcleos centrales de la "magia" bolañiana, es decir, aquellos elementos fascinantes que rompen con la lógica consumista de sociedades de mercado regidas por la oferta y la demanda. Cabe recordar que, según Bolaño, la única alternativa para que la vida no se desplome en los basurales de vacío es sumar la "magia" (épica, sexo, bruma dionisiaca y juego) a la ecuación de oferta y demanda. "Magia" es, entonces, eros.

Roberto Bolaño levanta sobre el crepitar del cuerpo uno de los pilares de Los detectives salvajes; desea descubrir el resplandor que separa la vida de la muerte, quiere que sus personajes se alimenten del cuerpo de otros hombres y otras mujeres y alcancen ese breve instante donde es posible cosechar una rosa entre los intersticios de las espinas, al decir del Marqués de Sade.

\section{BIBLIOGRAFÍA}

Ackerman, Diane. Una historia natural del amor. Barcelona: Anagrama, 2000.

Alberoni, Francesco. El erotismo. Barcelona: Editorial Gedisa, 2006.

Bakunin, Mijail. Estatismo y anarquía. Buenos Aires: Utopía Libertaria, 1989.

Bataille, Georges. El erotismo. Trad. Antoni Vincens. Barcelona: Tusquets, 1985.

Bhabha, Homi K. El lugar de la cultura. Trad. César Aira. Buenos Aires: Manantial, 2002.

Bolaño, Roberto. Los detectives salvajes. Barcelona: Editorial Anagrama, 1998.

Bolognese, Chiara. Pistas de un naufragio. Cartografia de Roberto Bolaño. Santiago: Editorial Margen, 2009.

Foucault, Michel. Historia de la sexualidad. La voluntad de saber. Madrid: Siglo XXI, 1980. Freud, Sigmund. El malestar en la cultura. Trad. López Ballesteros. Madrid: Biblioteca Nueva, 1981.

Giddens, Anthony. La transformación de la intimidad en Occidente. Trad. Benito Herrero. Madrid: Ediciones Cátedra, 1998.

Guattari, Félix. La révolution moléculaire. Paris: Editions Recherches, 1977.

Guerra, Lucía. Mujer y escritura. Fundamentos teóricos de la crítica feminista. México DF: Universidad Nacional Autónoma de México, 2007. 
Lamadrid, Silvia y Muñoz, Soledad. La investigación social en sexualidad en Chile: 1984-1994. Santiago: Universidad de Chile, Programa Interdisciplinario de Estudios de Género, 1996.

Marcuse, Herbert. Eros y civilización. Trad. Juan García Ponce. Barcelona: Editorial Ariel, 2008. Paz, Octavio. La llama doble. Amor y erotismo. México: Editorial Seix Barral, 1994.

Perlongher, Néstor. Prosa Plebeya. Ensayos 1980-1992. Buenos Aires: Ediciones Colihue, 1997. Reich, Wilhelm. Listen, little man!. New York: Octagon Books, 1971.

Rial, Julia Elena. "Los no lugares y el desarraigo en Los detectives salvajes de Roberto Bolaño". En: www.juliaelenarial.com/doc_download.aspx?document_id=14 (17/6/2007)

Vidal, Francisco. "Sexualidad y modernidad en Chile: una relación espúrea”... Cuerpo y sexualidad. Ed. Francisco Vidal y Carla Donoso. Santiago: LOM Ediciones, 2002.

Weeks, Jeffrey. El malestar de la sexualidad: significados, mitos y sexualidades modernas. Trad. Alberto Magnet. Madrid: Talasa, 1993.

Žižek, Slavoj. Visión de Paralaje. Buenos Aires: Fondo de Cultura Económica, 2006. 